\title{
EL ARCHIVO HISTORICO DE LA CAMARA OFICIAL DE COMERCIO E INDUSTRIA DE BURGOS
}

\author{
CARLOTA BUSTELO RUESTA, \\ ELISA GARCIA-MORALES HUIDOBRO \\ y NATALIA MARIN LOPEZ-OTERO \\ Gabinete de Asesores Documentalistas
}

\section{Introducción}

Por Real Decreto de 1886 se crean en España, a ejemplo francés, las Cámaras de Comercio, como instituciones necesarias para la organización de los intereses económicos del comercio y la industria y para la cooperación con el Gobierno. En este Decreto se autoriza la creación de varias Cámaras en distintos puntos de España, entre ellos Burgos.

La Cámara Oficial de Comercio e Industria de Burgos nace, pues, al amparo de esta disposición, el 6 de marzo de 1887. En su primera etapa, la pertenencia de comerciantes e industriales a las Cámaras tendrá un carácter voluntario, si bien sus funciones serán muy semejantes a las actuales. Se conservan en el Archivo documentos de gran valor para el estudio de esta etapa fundacional.

Será a partir de 1911, con la Ley de Bases para la reorganización de las Cámaras de Comercio, Industria y Navegación, cuando la Cámara de Burgos comience a cobrar más auge, al tiempo que aumenta la documentación que produce. Con esta Ley, las Cámaras se convertirán en organismos oficiales dependientes del Ministerio de Fomento. Su objeto será defender los intereses del comercio, la industria y la navegación, actuando al mismo tiempo como cuerpos consultivos de la Administración. Para llevar a cabo esta tarea se considerarán miembros de la Cámara y electores todos aquellos comerciantes e industriales que contribuyan al Tesoro por el ejercicio de su actividad, siendo los recursos de la Cámara el 2 por 100 de las contribuciones que satisfagan los electores por este concepto.

Esta Ley de Bases ha ido sufriendo numerosas modificaciones y ha sido complementada por distintos reglamentos, pero a lo largo de la Historia la actividad de la Cámara sigue siendo, esencialmente, la misma.

El funcionamiento de la Cámara de Comercio de Burgos queda recogido en el último Reglamento de Régimen Interior, de 1978. En él se establece que el órgano supremo es el Pleno, compuesto por 42 miembros elegidos 
entre distintas ramas del comercio y de la industria. Este Pleno se reúne, como mínimo, en seis sesiones ordinarias al año y tantas extraordinarias como se considere necesario. Serán las Actas de estas sesiones uno de los tipos documentales más interesantes del Archivo, puesto que en estas reuniones es donde se discuten todos los asuntos de interés de la Cámara. Además del Pleno, existe un Comité ejecutivo y unas Comisiones consultivas que apoyan el trabajo del Pleno.

La Cámara también cuenta con una organización administrativa al frente de la cual está el secretario. A través de ella se canalizan todos los servicios que presta la Cámara, que generan una documentación de gran interés. Entre ellos podemos destacar:

- Asesoría jurídica, técnica y económica a sus electores, que se plasma fundamentalmente en un gran volumen de correspondencia.

- Expedición de certificados de origen y de precios.

- Tramitación de la inscripción, renovación anual, etc., en los registros oficiales de importadores y exportadores del Ministerio de Comercio.

- Realización de cursos de formación profesional y empresarial.

- Intervención en arbitrajes de Derecho privado entre los elementos cuyos intereses representa.

- Elaboración del censo de electores, estadísticas de industrias y otras informaciones de utilidad para sus miembros.

Series documentales del Archivo de la Cámara de Comercio e Industria de Burgos

1. Documentación del Pleno. En esta documentación es donde quedan plasmadas las decisiones más importantes que toma la Cámara:

1.1. Libros de Actas. Constituyen la documentación más antigua de la Cámara, ya que se conservan desde el Acta fundacional hasta la actualidad.

1.2. Expedientes de las sesiones ordinarias de la Cámara. En ellos se recogen el Orden del Día, el Acta de la sesión y documentos que se han utilizado de base en las sesiones para el estudio de los diversos asuntos. Existen desde 1941 hasta 1977.

1.3. Expedientes de las sesiones extraordinarias. Con el mismo contenido que los anteriores, recogen las sesiones extraordinarias celebradas entre 1946 y 1977.

1.4. Ordenes del Día. En estos documentos se anotan los puntos a tratar en las sesiones. Existe una serie incompleta desde 1931 a 1976. 
2. Correspondencia. En este grupo se encuentra el grueso de la documentación producida por la Cámara, es decir, casi todos los documentos a que dan lugar los servicios que presta. Según el sistema de organización del Archivo, hay:

2.1. Correspondencia de entrada. Como su nombre indica, es la que recibe la Cámara. En los primeros tiempos está ordenada según la reciba el presidente o el secretario de la Cámara; después, por los asuntos a tratar en las sesiones $\mathrm{y}$, más tarde, por el número que recibe en el libro registro. Existe la serie completa desde 1912 a 1984 .

2.2. Correspondencia de salida. Es la que emite la Cámara, y está ordenada según un criterio alfabético de destinatarios. La serie va desde 1888 a 1983.

2.3. Libros registro de correspondencia de entrada. Desde 1930 a 1974.

2.4. Libros registro de correspondencia de salida. Desde 1941 a 1973.

2.5. Circulares. En su mayor parte es una documentación generada fuera de la Cámara, ya que proceden del Consejo Superior de Cámaras o de la Cámara de Comercio Internacional. Son, sin embargo, interesantes por los criterios de actuación que sugieren a las demás Cámaras.

3. Documentación económica interna. Es la que refleja la vida económica de la Cámara, y se presenta bajo diferentes tipos documentales:

3.1. Justificantes de gastos $e$ ingresos:

3.1.1. Libramientos. Son los justificantes de todos los gastos de la Cámara. La serie va desde 1920 a 1981.

3.1.2. Cargaremes. Son justificantes de ingresos a la Cámara. Desde 1921 a 1979.

3.2. Presupuestos ordinarios y liquidaciones. Documentos en los que se recogen las partidas presupuestarias de la Cámara y sus liquidaciones ante el organismo competente. Desde 1913 a 1978.

3.2.1. Presupuestos extraordinarios. Documentos referidos a partidas presupuestarias especiales entre 1966 y 1979.

3.3. Documentos de recaudación. Relacionados con la recaudación del 2 por 100 de las contribuciones, presentan varios tipos documentales: 
3.3.1. Relaciones de Hacienda de las Juntas de evaluación global de beneficios, con las que la Cámara elabora el censo de electores. Desde 1958 a 1978.

3.3.2. Relaciones de los recibos de recaudación y liquidaciones. En estos documentos aparecen las recaudaciones de la Cámara en las distintas zonas de la provincia con su correspondiente liquidación ante el Servicio de Contribuciones de la Diputación Provincial. La serie va desde 1932 a 1983.

3.4. Libros contables. Son el tipo documental que presenta menor continuidad. Varían a lo largo de la historia de la Cámara, y son de distintos tipos:

3.4.1. Libros de Cuentas Corrientes con los recaudadores de Hacienda. Desde 1932 a 1942.

3.4.2. Libros de recaudación de la Cámara. Desde 1942 a 1979.

3.4.3. Libros de Cuentas de Tesorería. Según los presupuestos de ingresos y gastos desde 1887 a 1980.

3.4.4. Libros de Cuentas del Servicio de Comercio Exterior. Desde 1967 a 1981.

3.4.5. Libros de Cuentas Corrientes con el Servicio de Contribuciones de la Diputación. Desde 1949 a 1979.

3.4.6. Libros de Gastos e Ingresos, 1921-1979.

3.4.7. Libros de Cuentas de Transportes, 1936-1939.

3.4.8. Libros contables varios. De vigencia temporal.

3.5. Estados de situación económica de la Cámara. Son expedientes elaborados por la propia Cámara desde 1952 a 1979.

3.6. Documentos bancarios. Justificantes de Bancos y expedientes sobre préstamos pedidos por la Cámara. Desde 1967 a 1982.

4. Documentación DE RÉGIMEn INTERNo. En este grupo aparecen documentos de carácter administrativo interno de la Cámara:

4.1. Personal. Asuntos varios sobre el personal de la Cámara: oposiciones, sueldos, expedientes, etc. Desde 1913 a 1983.

4.2. Documentos electorales. Están relacionados con la renovación de los miembros del Pleno. Desde 1912 a 1966. 
5. Expedientes y asuntos. Este apartado de documentos agrupa temas diversos que, por su importancia, la Cámara ha decidido separar de la documentación habitual, es decir, de la correspondencia. Está subdividido en varios apartados:

5.1. Asuntos generales.

5.2. Asuntos locales.

5.3. Polo de Desarrollo.

5.4. Petróleo.

5.5. Registro de Importadores.

5.6. Ferias y Exposiciones.

5.7. Asambleas y Congresos.

5.8. Cursos.

6. Censos y estadísticas:

6.1. Censos de electores de la Cámara. En un principio están realizados por zonas recaudatorias, hasta 1973, en que aparecen distintos listados: alfabético, de epígrafes, de municipios... Se confeccionan a partir de los datos que proporciona Hacienda sobre los contribuyentes. La primera lista de electores data de 1890-1907, cuando no era obligatoria la pertenencia a la Cámara. La serie de censos comienza a partir de 1912. Faltan los años 1913, del 1922 al 1928 y el de 1941 para que sea completa hasta la actualidad.

6.2. Estadísticas. Son de carácter vario y no constituyen una serie continuada.

\section{Valor bistórico del Archivo de la Cámara}

El Archivo de la Cámara de Comercio e Industria de Burgos se encuentra a disposición de los investigadores, previa autorización del secretario, desde mediados del año pasado, en que se nos encargó su organización. Su valor para la investigación se puede establecer en dos vertientes:

En primer lugar, para el estudio de la historia de la propia Cámara: a través de las actas del Pleno y de los documentos de carácter interno, se puede analizar su evolución, los servicios que ha prestado a la industria y al comercio 
a lo largo de casi un siglo de existencia, qué personas han conformado sus órganos directivos, cómo han sido elegidas, sus relaciones con otras Cáma. ras, etc.

En segundo lugar, para el estudio de la actividad comercial e industrial de Burgos durante este siglo. Los censos electorales son una fuente de gran valor para conocer la distribución sectorial de estas actividades y sus variaciones a lo largo de los años. Investigar sobre las razones de estos cambios, y fenómenos como la expansión del Polo de Desarrollo de Burgos, son tareas que encuentran sus bases en el Archivo de la Cámara.

Los fondos documentales se encuentran depositados en cajas de archivo, y como instrumentos de búsqueda existen un inventario topográfico y un fichero que se corresponde con las series documentales antes expuestas. Las fuentes primarias pueden completarse, además, con las colecciones de prensa local y las publicaciones de la propia Cámara que se encuentran depositadas en la Biblioteca.

Queda, por último, señalar el valor de esta iniciativa por parte de la institución, que abre un nuevo camino al desarrollo de la historia económica y que marca un ejemplo a seguir por el resto de las Cámaras del país. 